\title{
TECHNOLOGY AND MARKET OPPORTUNITIES IN FIBER CEMENT COMPOSITES FOR SMALL SCALE ENTERPRISES IN NIGERIA
}

STEPHEN O. AMIANDAMHEN

(Received 20 April 2012; Revision Accepted 14 November 2012)

\begin{abstract}
Solving problems of unemployment and developing new materials for buildings requires moving beyond the traditional approaches to more economical, environmentally benign performance models and design properties. New approaches should develop models based on the literature and a full understanding of the root causes of failure, derived from careful failure analysis. One of the main drivers of the development efforts in fibre based composites is the trend towards greater environmental awareness and the health hazards associated with the utilization of asbestos fibres. The key to effectively developing marketable fibre cement composites for use as building materials that can be used for construction of safe and affordable structures is to identify the research and development and market needs for such products. This paper looks into the empirical production and market opportunities in terms of product performance accruable to locally manufactured fibre cement ceiling boards.
\end{abstract}

\section{KEY WORDS: Fibre Cement Boards, Production, Market Needs, Product Performance}

\section{INTRODUCTION}

The forest as a naturally renewable resource has been used as a principal source of bio-energy and building materials for centuries. The global forest harvest increased substantially from 1950 and reached its climax in 1990 because of the environmental concerns and Government imposed restrictions on deforestation (FAO, 2001). Resulting increases in the demand for wood and fibre products, coupled with the declining conventional raw materials provides a unique opportunity for developing new generations of renewal, sustainable, and materials efficient bio-based composites. As the world's population need for safe, affordable, environmentally-friendly shelter is expected to increase substantially, it requires seeking some new alternatives for building materials. As a direct result, this provides an opportunity to develop new fibre-based composites and utilize the low-value forest resources. The development and understanding of building materials using fibre-cement composites as ceiling applications arbitrarily became imperative because of the growing concern about the health hazards associated with the use of asbestos fibres. Typically, fibre reinforced concrete have been shown to be effective in improving structural performance in members under gravity loads, as well as in increasing shear strength, ductility, energy dissipation, and damage tolerance in members subjected to reversed cyclic loading (Bayasi and Gebman 2002, Jevtic et al. 2008). It would be significant to note that fibre-cement composites are offering great possibilities in the field of research and combination of more advanced solutions in order to keep up with contemporary trends. It has been successfully employed in slabs, architectural designs, footings, ceilings, roofing and other structural applications.

\section{Materials Used}

The manufacture of fibre cement involves using both organic and inorganic raw materials. The organics include fibres and defoamers, while the inorganics include Portland cement, silica, water, and calcium salts for strength improvements. The major components involve cement, water, silica, and fibres. Varieties of fibres exist for reinforcement with concrete. Some of the fibres include natural fibres from wood and non-wood, glass roving, steel, asbestos, recycled papers etc. The fibres of choice must not only be technically viable with respect to strength and toughness, but must also clearly be economically acceptable and compatible with the process of manufacture (Moslemi, 2008). Addition of fibres to cement delays and controls the tensile cracking of the matrix (Olorunnisola, 2007) and imparts a lighter weight and a degree of flexibility that are important to the market place (Moslemi, 2008). In western Nigeria where fibre-cement composite boards are gradually penetrating the local market, recycled papers serve as source of fibres for small scale enterprises, which are yet to explore the potentials of natural fibres. Waste papers will continue to be the fibres of choice for many local manufacturers due to the advantages they offer including economics which is critical in making these products price competitive. Though, it is evident that recycled papers have relatively low fibre length after

Stephen O. Amiandamhen, Department of Forestry and Wildlife, Faculty of Agriculture, University of Benin, Benin City, Nigeria. 
pulverization (Amiandamhen, 2011), its impact as fillers for strength enhancement cannot be under-estimated. More so, natural fibres used as reinforcement in waste paper-cement matrix improve strength and toughness of the resulting composites significantly (Oladele et al., 2009).

\section{The Technology}

The most popular technology used in fibrecement manufacturing is the Hatschek process dating back to 1911 . It is named after its developer Ludwig Hatschek of Austria who based it on the pulp and paper manufacturing process. In Western Nigeria, the technology employed in manufacturing ceiling boards, though empirical is nonetheless efficient since it produces composite boards of even thickness and comparable strength properties (Amiandamhen, 2011).

The product manufacturing involves soaking of waste papers in cylindrical drums for a period of time depending on the nature of the paper. The second stage is the pulverization of the wet fibre by hammer milling. Thereafter, the resultant pulp slurry is mixed with cement paste with adequate water to allow for good formation in the mould. The pulp-concrete paste is then casted in a mould whose dimensions have been predetermined and suitable for the local market. After 24 hours, the fibre cement composite is de-moulded, and the formed board is kept in an open environment for 28 days in order for the concrete to cure.

A simple flow chart for the production process is presented in Figure 1 and Plate 1.

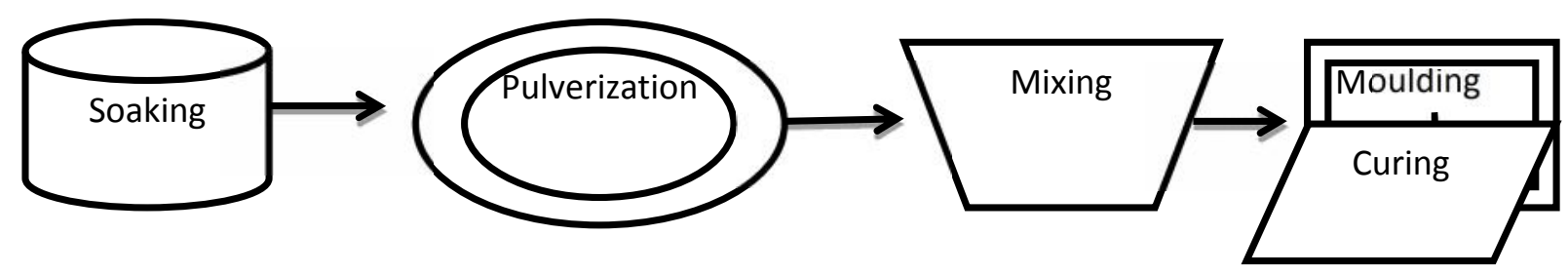

Figure 1: A flow chart for fibre cement production process



(a) Soaking

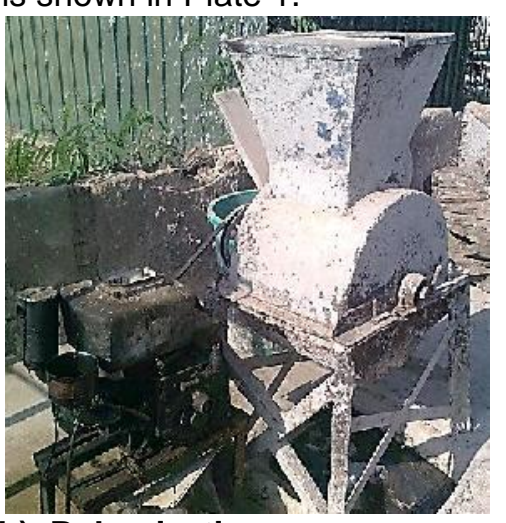

(b) Pulverization

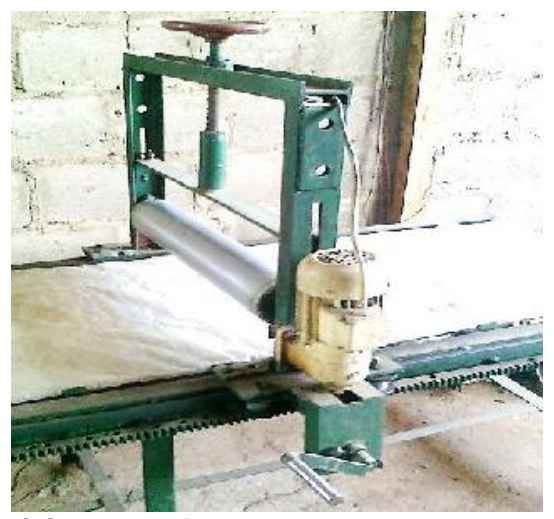

(c) Moulding

Plate 1: Fibre cement production

\section{Opportunities and Market}

Contemporary Structural engineering is permanently setting new conditions concerning the quality of building materials especially wood and fibre composites. These conditions have to be completely fulfilled in order to increase the durability, serviceability, and cost-effectiveness of modern buildings (Jevtic et al., 2008). In Western Nigeria, the penetration of fibre cement boards in local housing and construction markets has been steady over time. There has been a substantially increased acceptance of fibre cement in applications that were traditionally supplied by wood and other materials.

Based on the report of research findings (Amiandamhen, 2011), fibre cement boards present favourable opportunities that are important to the market place. Some of these market considerations are highlighted below:

- $\quad$ Fibre cement boards are highly durable and are not easily attacked by degrading insects or fungi.

- Fibre cement boards have high fire resistance and moderate water absorptivity. The water absorptivity of the composite places it as an efficient ceiling material to withstand prolonged water retention if a break occurs in the roof. Oladele et al. (2009) found that the water absorptivity of the composites depends on the fibre mass fraction employed in the matrix, increasing with increasing fibre percentage. However, as the amount of fibre increases in the composite, a decline in fibre cement density results (Moslemi, 2008). 
- Fibre cement boards have high impact resistance as a result of its toughness. Fracture toughness is an important parameter as it signifies the resistance of the fibre cement to fracture development and ultimately the failure of the product (Moslemi, 2008).

- Though it is believed that pulverized fibres do not provide any significant bridging properties upon micro-crack development and generally act more as fillers, studies revealed that the tensile and flexural strength of the boards are comparable to gypsum boards, plaster of paris and fibre boards used for ceiling applications.

- There is a high flexibility of design of the finished product offering it an aesthetic value as an interior decorator.

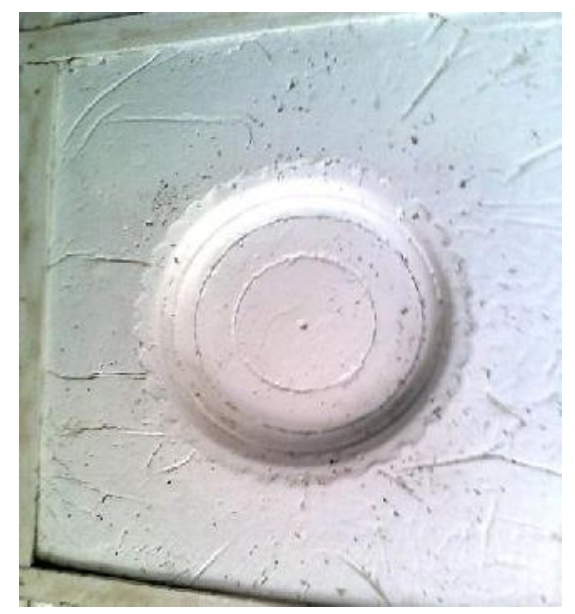

Plate 2: Design flexibility of the boards

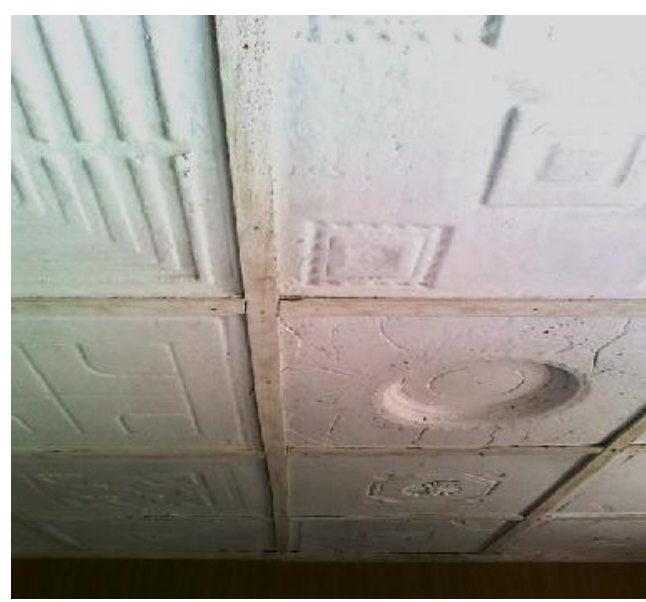

Plate 3: Fibre cement ceiling boards in application

\section{CONCLUSIONS}

In conclusion, the production of fibre cement boards presents a successful business, as the ceiling boards are gradually penetrating the local construction
- Finally, the prices for these boards have been strengthening in the past number of years but currently are levelling due to the local market conditions at N250 per square feet of the boards.

Fibre cement ceiling board manufacturing continues to be considered a profitable business with respectable margins although it is encountering a soft market at this time. It is likely that product diversification will continue in the years ahead in addressing market opportunities that are likely to emerge.

Some of the designs and application of the fibre cement boards are shown in Plates 2 and 3.

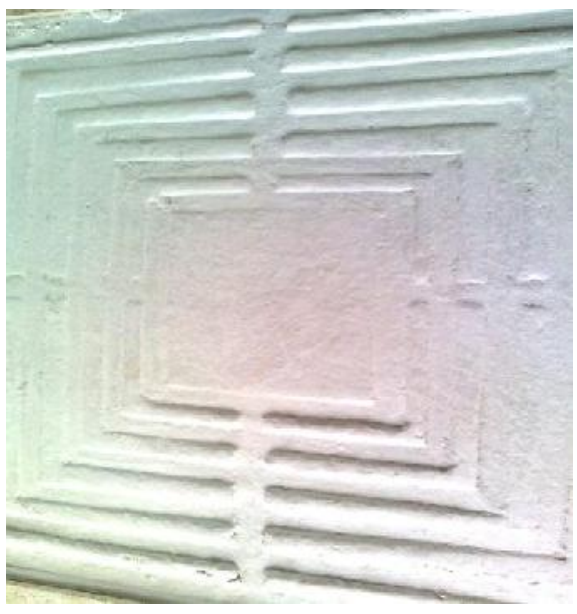

markets. Waste papers will continue to be the fibres of choice for many local manufacturers due to the economic advantages which is critical in making the products price competitive. With fibre products, the 
quality and supply will be of concern as they seek to offer product replacement as well as new applications in the market place.

In summary, fibre cement boards present a low cost environmentally-friendly building materials that are insects and fungi resistant. To enhance the product's sustainability in the market, the following considerations are necessary:

- Economic considerations including analysis of strength, weakness, opportunities, and threats and the target market.

- Environmental considerations including recyclability and emission of toxic materials.

- Research and Development including raw material preparation, process improvement and optimization, performance standard and specification, and recommendations.

- Advertisement and sales including demonstration houses, sales distribution, customer services and education.

\section{REFERENCES}

Amiandamhen, S. O.,, 2011. Strength and Sorption Properties of some selected Paper-Cement Ceiling Boards in Ibadan. MSc Seminar, Univ. Ibadan, Nigeria, 25pp.
Bayasi, Z. and Gebman, M., 2002. Reduction of Lateral Reinforcement in Seismic Beam-Column via Application of Steel Fibres. $\mathrm{ACl}$ Structural Journal 99 (6):772-780.

Food and Agriculture Organization (FAO) of the United Nations, 2001. State of the World's Forest, 2001.

Jevtic, D., Zakic, D. and Savic, A., 2008. Modelling of Properties of Fibre Reinforced Cement Composites. Journal of Architecture and Civil Engineering 6(2):165-172.

Moslemi, A., 2008. Technology and Market Considerations for Fibre Cement Composites. $11^{\text {th }}$ International Inorganic-Bonded Fibre Composites Conference (IIBFCC), 2008, pp.113-129.

Oladele, I. O., Akinwekomi, A. D., Aribo, S. and Aladenika, A. K., 2009. Development of Fibre Reinforced Cementitious Composite for Ceiling Application. Journal of Minerals and Materials Characterization and Engineering 8(8):583-590.

Olorunnisola, A. O., 2007. Effects of Particle Geometry and Chemical Accelerator on Strength Properties of Rattan-Cement Composites. African Journal of Science and Technology 8(1):22-27. 